\title{
Estimating diluted bitumen entrained by suspended sediments in river rapids using $\mathrm{O}_{2}$ absorption rate
}

\author{
S. Perez ${ }^{1} \cdot$ P. Furlan ${ }^{2} \cdot$ S. Ellenberger ${ }^{3} \cdot$ P. Banker $^{3}$
}

Received: 11 August 2014/Revised: 8 April 2015/Accepted: 4 August 2015/Published online: 7 September 2015

(C) Islamic Azad University (IAU) "(outside the USA)" 2015

\begin{abstract}
Suspended sediments and river rapids can cause oil slicks to fragment and sink, greatly complicating the cleanup process of a spill. Responders need methods for estimating the severity of spilled oil entrainment in rivers in order to properly plan resource allocation. This work presents a novel technique for predicting the amount of oil entrained by suspended sediments in rivers, using the atmospheric oxygen absorption rate of rivers as a way to estimate the surface turbulence. The technique may be used by measuring the gas transfer velocity or by using parametric equations for gas transfer velocity based on river parameters such as slope, depth, and discharge rate. In very turbulent rapids, $13 \%$ of a diluted bitumen slick could be brought down by clay-sized sediments in about $10 \mathrm{~min}$ if the sediment concentration is high enough, and $80 \%$ would be brought down in $2 \mathrm{~h}$.
\end{abstract}

Keywords Dilbit · Diluted bitumen · Enbridge spill · Kalamazoo River spill · River oil spill · Suspended sediments and oil spills

S. Perez

perezs@usmma.edu

1 Department of Marine Engineering, U.S. Merchant Marine Academy, Kings Point, NY 11024, USA

2 Department of Mathematics and Science, U.S. Merchant Marine Academy, Kings Point, NY 11024, USA

3 Midshipman 1st Class, U.S. Merchant Marine Academy, Kings Point, NY 11024, USA

\section{Introduction}

The purpose of this work is to provide responders to river oil spills with a tool for estimating the amount of oil entrained by suspended sediments in the river. The entrained oil can sink, greatly complicating its cleanup.

The USA and other developed countries are covered by extensive webs of pipelines carrying petroleum products of different types. In the USA alone, there are hundreds of thousands of miles of pipelines carrying liquid petroleum products (American Petroleum Institute 2014).

These pipelines can run very close to rivers, and the possibility of a spill always exists. One example is the 2010 Kalamazoo River spill in Michigan, where approximately one million gallons of diluted bitumen was spilled into the river (EPA 2014). According to a document filed by Enbridge Energy Partners (Enbridge 2014) with the US Securities and Exchange Commission, the cost of cleaning up the Kalamazoo River spill is estimated at $\$ 1.2$ billion.

The number of pipeline spills is increasing because of greater pipeline usage: Over the last decade, there have been about 35 pipeline spills per year, compared with about 6 per year in the 1970s (Jernelov 2010). Due to increased tanker safety and regulation, spills from tankers have diminished greatly while pipeline spills have experienced the opposite trend.

In the USA, petroleum products are also being carried in railroad cars which can travel close to rivers. In 2014, one of these trains overturned and spilled tens of thousands of gallons of oil into the James River in Virginia (NY Times 2014).

Oil that is normally buoyant can sink due to interaction with sediments. Khelifa et al. (2005a) report that fine grains of sediment adsorb on the surface of oil droplets or as flocculated aggregates. For ocean spills, this typically 
happens in beach areas where wave action drives the floating oil down into the sand. In open ocean conditions, the sediment load is too low to be a significant factor in the sinking of oil (Lehr 2010). However, sediment concentrations greater than $7000 \mathrm{mg} / \mathrm{L}$ are possible in rivers (Vanoni 2006), enabling a substantial amount of oil entrainment by sediments. For example, approximately 80,000-280,000 gallons of oil from the Kalamazoo River spill is estimated to have sunk to the river bottom, requiring the dredging of hundreds of thousands of cubic yards of bottom mud (EPA 2013)

This study involves two phenomena: the solution of gases into liquids (governed by the gas transfer velocity) and the entrainment of oil by suspended sediments in water. We hypothesize that the gas transfer velocity of atmospheric oxygen into water can be used as a proxy for turbulence for the scaling of laboratory oil entrainment results.

The flux of atmospheric gas into a liquid is driven by a concentration gradient between the gas in the atmosphere and the gas in the liquid, and is governed by the relation: (Danckwerts 1970):

$\frac{\mathrm{d} C}{\mathrm{~d} t}=\operatorname{GTV}\left(C_{\mathrm{sat}}-C\right)$

GTV is the gas transfer velocity (length/time), $C$ is the dissolved oxygen concentration (mass/volume) in the liquid, and the subscript sat refers to the saturation value of the dissolved gas in the liquid. $\frac{\mathrm{d} C}{\mathrm{~d} t}$ is the rate of change in the gas concentration per unit area with respect to time.

A gas moving from the atmosphere to water requires gas molecules to move through a surface boundary layer in the atmosphere and a surface boundary layer through the water. For gases that are sparingly soluble (such as atmospheric $\mathrm{CO}_{2}$ and $\mathrm{O}_{2}$ ), the water side controls the rate of solution, since the solution rate depends on molecular diffusivity. Diffusivities in liquids are 2-3 orders of magnitude less than those in air (Banerjee and MacIntyre 2004). Thus, turbulence on the liquid side controls the rate of gas transfer.

Gas transfer velocity measurements in lakes and large bodies of water can have significant amounts of scatter, confounding attempts to determine accurate parametric fits to GTV (in particular for $\mathrm{CO}_{2}$ for global warming studies). The reason for this is the influence of a variety of factors such as the wind speed (Wanninkhof 1992; Wanninkhof and McGillis 1999), wind fetch (Frost and Upstill-Goddard 2002; Borges et al. 2004; Guerin et al. 2007), tidal currents (Borges et al. 2004; Zappa et al. 2007), rainfall (Ho et al. 1997, 2007), breaking waves (Zappa et al. 2004), thermal convection (Schladow et al. 2002; Eugster et al. 2003), organic matter or suspended matter (Abril et al. 2009; Calleja et al. 2009), and surfactants (Frew et al. 1990;
McKenna and McGillis 2004). Banerjee and MacIntyre (2004) consider thermal convection to be the most influential, since it could be influenced by cloud cover, season, time of day, changing air temperatures, and humidity.

However, river rapids GTV measurements, due to the inherent mixing and turbulence involved, are probably not as influenced by wind speed or thermal convection. Recently, researchers (Vachon et al. 2010) have underscored the importance of turbulence in gas transfer velocity correlations (to the exclusion of other parameters listed previously). Thus, we can expect river rapid GTV values to demonstrate less scatter than lake or ocean values.

Like the gas transfer velocity, the rate at which oil is entrained by sediments also depends on the water surface turbulence.

Zhang et al. (2010) report that the first laboratory experiments of the interaction of oil and minerals and the formation of oil-mineral aggregates (OMA) were conducted by Delvigne et al. (1987) and Payne et al. (1987, 1989).

Payne et al. (1987) developed an expression for mass of oil sunk from oil droplets due to interaction with sediments in a stirred container. The authors found that the oil entrainment/sinking rate is a function of oil droplet concentration, sediment concentration, an experimentally derived constant, and the square root of the turbulent shear ratio (the rate of energy dissipation of the flow divided by the viscosity). The authors' equation, although important in showing the effect of various parameters, cannot be used directly for river calculations as the energy dissipation rate and constant must be determined for each flow and oil type. The authors' work was conducted in the context of ocean spills, where sedimentation of the oil can be beneficial to dispersing the slick.

McCourt and Shier (1999) measured the amount of oil which sank to the bottom of a container under agitation, using water and sediments from an Alaskan river. They found that temperature of the water, dissolved solids, degree of agitation, and post-shaking rest time affected the amount of oil entrained by the sediments. They expressed their results for mass of oil entrained as a fraction of the total sediments sinking to the bottom. In McCourt and Shier (2001), the authors applied their laboratory methodology to six Alaskan rivers, and determined that the river sediments had a large capacity to entrain spilled crude oil. However, these studies did not relate laboratory results to turbulence levels in actual rivers; their purpose was to develop upper bounds for oil entrainment by sediments in river spills.

Bragg and Owens (1994) described how slicks are naturally removed over time when sediments and oil droplets combine to form oil-mineral aggregates. Numerous studies have been carried out dealing with oil- 
mineral aggregates as a method of dispersing oil slicks, but which have applicable results to the study of sinking sediments in rivers. These studies have suggested that turbulent energy, type of dispersant, and sediment characteristics could influence the amount of oil entrained by the mineral phase (Ajijolaiya et al. 2006; Khelifa et al. 2005b; Stoffyn-Egli and Lee 2002). Ma et al. (2008) also demonstrated that increased turbulence energy can increase the interaction between oil and suspended minerals. Ajijolaiya et al. 2006, Guyomarch et al. 2002, and Stoffyn-Egli and Lee 2002 showed that the formation of oil-mineral aggregates is enhanced by mineral properties such as particle size, surface area, concentration, and surface chemistry. The kinetics of OMA formation were investigated by Payne et al. $(1989,2003)$ and Hill et al. (2002).

Khelifa et al. (2005c) performed Monte Carlo simulations to calculate the effect of oil density, sediment type, sediment size, energy dissipation rate, and sediment concentration on oil-mineral aggregate formation. These studies demonstrated that increasing turbulence dissipation rate has the effect of reducing the size of oil droplets and increasing oil entrainment.

In Canadian Government Technical Report (2013), the authors applied sediment and water mixtures to diluted bitumen slicks in salt water, and subjected the slicks to wave action in a 32-m-long, 0.6-m-wide wave tank. They found that high-energy waves caused oil with sediments to sink or be dispersed as floating tar balls, depending on the degree of weathering of the slick. The purpose of this test was to determine whether diluted bitumen would sink, and thus, no attempt was made to measure the rate at which sediments and oil interact and sink.

Perez et al. (2014) conducted similar laboratory experiments to McCourt and Shier (1999) using clay-sized sediments, but expressed their results as oil entrained per unit mass of slick rather than per mass of sinking sediment. The authors scaled their results to actual river spills using the wave height as a scaling parameter, making it possible to estimate the amount of oil entrained by sediments in a real spill.

Perez et al. (2014) used intermediate fuel oil (IFO) and heavy fuel oil (HFO) mixed with water and sediments, and agitated the mixture in small containers using an automatic shaker. The mixture was then allowed to rest in a separatory funnel for 3 days, and the oil-covered bottom sediments were removed, after which a spectrophotometer was used to determine the mass of oil entrained in the sediments.

The authors found that the less viscous IFO was brought down by the sediments at about 20 times greater rate than HFO. However, there was some uncertainty as to whether the scaling assumption could be applied to large wave heights, and thus, the authors limited the scope of their work to small rapids-no greater than Class 2 on the International Scale of River Difficulty (USDOI 2014), with waves not exceeding about $0.5 \mathrm{~m}$. In addition, using waves as a scaling factor requires estimating the fraction of the river surface covered by waves and an average wave height of the waves, which may not be easy to do for long river stretches.

Due to the shortcomings of using the wave height as a scaling parameter, the authors of this paper propose using river $\mathrm{O}_{2}$ absorption constants (gas transfer velocity) as a scaling factor to extrapolate laboratory results to real-life rivers. The method is applicable to any size rapids, using the atmospheric $\mathrm{O}_{2}$ gas transfer velocity.

The gas transfer velocity of rivers is an important parameter related to a river's ability to absorb pollutants. In addition, depletion of dissolved $\mathrm{O}_{2}$ in a river can be deadly to aquatic life. For these reasons, the study of the $\mathrm{O}_{2}$ absorption capability of streams and rivers has received a considerable amount of attention, with numerous studies available reporting $\mathrm{O}_{2}$ absorption constants as well as techniques for estimating these constants. By using readily available $\mathrm{O}_{2}$ absorption data, responders to river oil spills can use the techniques presented in this work to make quick estimates of quantities of oil entrainment by sediments.

Un-weathered diluted bitumen (dilbit) crude oil from the Western Canadian Sedimentary Basin is used in this study, but the techniques applied are also applicable to other oil products.

All testing was conducted in a laboratory setting in Long Island, NY, USA, from July 2014 to January 2015.

\section{Materials and methods}

\section{Oil entrainment and gas transfer velocity measurements}

Laboratory experiments were conducted to determine how sediments and oil interact. The procedure used was very similar to that described in Perez et al. (2014). Plastic containers measuring $14 \mathrm{~cm}$ in height and $10 \mathrm{~cm}$ in diameter were partially filled with $250 \mathrm{cc}$ of tap water (240 ppm total dissolved solids) and a mixture of claysized kaolinite. Two grams of un-weathered diluted bitumen crude oil (dilbit) obtained from the Canadian Association of Petroleum Producers was gently placed on the surface of the water/kaolinite mixture. The resulting slick had about $1 \mathrm{~cm}$ of space to the container wall-the slick did not cover the entire free surface. The containers with the mixtures of oil, water, and sediments were then agitated for 1 min using a Burrell wrist action shaker that shook the 
containers along one lateral axis. Before the test began, the dilbit was shaken for $10 \mathrm{~min}$ to ensure uniformity, and stored in a refrigerator before and after testing to prevent degradation.

After shaking, the mixtures were carefully transferred to a separatory funnel and allowed to rest for 3 days to allow the sediments to sink to the bottom. This was ample time, as the water was clear once the time had elapsed. The sediments were then drained into a clean container, and $10 \mathrm{cc}$ of clear mineral oil was added. Any entrained dilbit was absorbed by the mineral oil, resulting in a change in light absorbance of the mineral oil proportional to the amount of dissolved dilbit (Harris 2010). The light absorbance was measured using a Bausch and Lomb Spectronic 20 spectrophotometer calibrated by dissolving known quantities of dilbit into the mineral oil.

Two types of laboratory oil experiments were performed: to determine the effect of varying sediment concentration on oil entrainment and to determine the effect of varying turbulence on oil entrainment.

Sediment concentrations tested ranged from 250 to $8000 \mathrm{mg} / \mathrm{L}$. Turbulence was varied by allowing the water volume to range from 100 to $450 \mathrm{cc}$. It was found that increasing the water level in the container resulted in an increase in turbulence, as demonstrated by larger waves, increasing oil entrainment, and increasing $\mathrm{O}_{2}$ solution rate in the water.

The amount of $\mathrm{O}_{2}$ dissolved in the water during agitation was measured before mixing with oil and sediments. Since the water used was close to the saturation value of dissolved oxygen, the water was boiled and allowed to cool in a sealed container to room temperature. This caused the $\mathrm{O}_{2}$ levels to drop from approximately 8 to $5 \mathrm{mg} / \mathrm{L}$.

Dissolved oxygen was measured using a Vernier dissolved oxygen probe connected to a Vernier computer interface. Readings were taken every 15 for $45 \mathrm{~s}$, and the gas transfer velocity was calculated by integrating Eq. (1) (Edwards and Penney 2008):

GTV (Gas Transfer Velocity)

$$
=\frac{\ln \left(\mathrm{O}_{2 \mathrm{sat}}-\mathrm{O}_{2}\right)_{0}-\ln \left(\mathrm{O}_{2 \mathrm{sat}}-\mathrm{O}_{2}\right)_{t}}{\Delta t}
$$

The subscript sat refers to the saturation level of $\mathrm{O}_{2}$ dissolved (which depends on the water temperature and atmospheric pressure), subscript 0 refers to a reading taken at the beginning of a 15 -s time period, and subscript $t$ is a reading after $15 \mathrm{~s}$ has elapsed. $\Delta t$ is the time elapsed.

Since the water under agitation very quickly moves toward saturation of $\mathrm{O}_{2}$, it was not feasible to extend measurements over longer periods of time.

\section{Scaling laboratory oil entrainment results to real rivers}

As discussed earlier, Payne et al. (1987) calculated that oil entrainment by sediments changes as the energy dissipation rate to the $1 / 2$ power. Pope (2000) states that the dissipation rate of high-turbulence flows changes as turbulent velocity fluctuations to the 3 rd power, which are of the same order as the flow velocity $u$. This leads to:

oil entrainment rate $\sim u^{\frac{3}{2}}$

Hall et al. (2012) measured the $\mathrm{O}_{2}$ absorbed on the Colorado River, in tranquil to very turbulent stretches of the river. Figure 1 shows Hall's results. On the $x$-axis is the river slope, while the $y$-axis shows the gas transfer velocity (GTV) in $\mathrm{cm} / \mathrm{h}$.

The scatter in the plot is due to the fact that $\mathrm{O}_{2}$ readings were taken across each portion of the river and reflect the varying turbulence level from shore to shore.

The Manning equation (White 2010) shows that, assuming uniform flow:

$V\left(\frac{m}{s}\right)=R_{h}^{2 / 3} S^{1 / 2} / n$

where $V$ is the river velocity $(\mathrm{m} / \mathrm{s}), R_{\mathrm{h}}$ is the hydraulic radius (m), $S$ is the slope of the river $(\mathrm{m} / \mathrm{m})$, and $n$ is the Manning roughness coefficient.

From the Bernoulli equation (White 2010), we know that the maximum wave height $h$ possible with a given flow velocity $V$ is given by:

$V=(2 g h)^{1 / 2}$

By combining Eqs. (4) and (5), we show that the maximum wave height varies linearly with the slope:

$(2 g h)^{1 / 2}=R_{h}^{2 / 3} S^{1 / 2}$

House Rock Rapids in the Colorado River have a slope

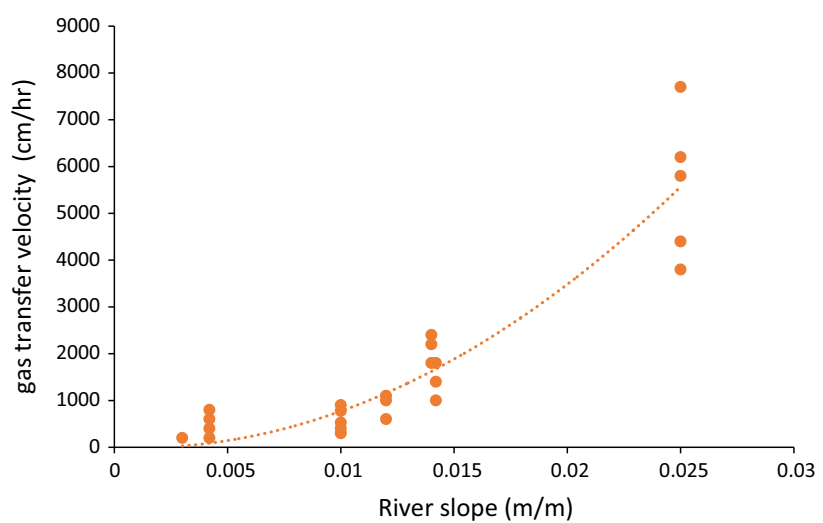

Fig. 1 Results of Hall et al. (2012), showing the effect of river slope on the rate at which $\mathrm{O}_{2}$ is absorbed in a river 
of 0.025 (Hall et al. 2012), and are represented in Fig. 1 as the point with the highest gas transfer velocity. Video footage of the rapids from social media shows that the maximum wave height at these rapids is about $2 \mathrm{~m}$. The maximum river slope of 0.025 in Fig. 4 then corresponds to $2 \mathrm{~m}$ maximum wave height, and a river slope of zero corresponds to zero wave height. A linear change between 0 and $2 \mathrm{~m}$ can then be assumed according to Eq. (6). The wave height can then be converted to flow velocity by Eq. (5).

Analysis of Fig. 1 with the $x$-axis converted to flow velocity shows that, for GTV values up to about $1000 \mathrm{~cm} /$ h,

$\mathrm{GTV} \sim u^{2.4}$

Combining Eqs. (3) and (7) and making a ratio of oil entrained in the river to oil entrained in the laboratory, we obtain for river GTV values less than or equal to $1000 \mathrm{~cm} /$ h:

$\frac{\text { Oil entrained in the river }}{\text { Oil entrained in the laboratory }}=\left(\frac{\mathrm{GTV}_{\text {river }}}{\mathrm{GTV}_{\text {lab }}}\right)^{0.63}$

For GTV values greater than $1000 \mathrm{~cm} / \mathrm{h}$, the slope of Fig. 1 increases. Analysis of Fig. 1 with the $x$-axis converted to flow velocity yields:

$\mathrm{GTV} \sim u^{4.2}$

Combining Eqs. (3) and (9) and making a ratio of oil entrained in the river to oil entrained at $1000 \mathrm{~cm} / \mathrm{h}$, we obtain for river GTV values beyond $1000 \mathrm{~cm} / \mathrm{h}$ :

Oil entrained in the river

Oil entrained in the river at $1000 \frac{\mathrm{cm}}{\mathrm{h}}$ using eq. (8)

$$
=\left(\frac{\mathrm{GTV}_{\text {river }}}{\mathrm{GTV}_{\mathrm{lab}}}\right)^{0.4}
$$

The exponent in Eq. (8) was calculated as 0.36, but was rounded to 0.4 .

With Eqs. (8) and (10), the oil entrained by sediments in a river can be estimated once laboratory values of GTV and oil entrainment are known, along with river GTV values.

\section{Results and discussion}

\section{Oil entrainment}

The oil entrainment results are shown in Fig. 2. The $x$-axis shows the sediment concentration in $\mathrm{mg} / \mathrm{L}$, and the $y$-axis the mass of dilbit absorbed by sediments per mass of slick per minute. The plot shows that the oil absorbed by the sediments increases with sediment load, but that at about $1000 \mathrm{mg} / \mathrm{L}$ the effect of sediment concentration appears to level off. This trend is consistent with the findings of Guyomarch et al. (1999).

The plot also shows that the scatter in the data becomes larger at higher sediment concentrations. The scatter is quite high, and is probably due to the low dilbit concentration levels, as even a very small amount of contamination has a pronounced effect. In addition, as discussed below, there is a degree of randomness to performing agitation (sloshing) tests in a tank. The scatter in our results and the trend of increasing scatter with sediment load are similar to those encountered by other researchers (Guyomarch et al. 1999; Ajijolaiya et al. 2006).

Roughly $50 \%$ of the oil adhered to the container walls during the agitation process, which we assumed occurred gradually over the 1-min agitation. For this reason, when calculating the oil entrained by sediments per mass of slick, we used $75 \%$ of the original mass of the slick $(75 \%$ of $2 \mathrm{~g}$, or $1.5 \mathrm{~g}$ ) as the mass of the slick.

It is noted that when compared with similar testing done with intermediate fuel oil (IFO) (Perez et al. 2014), the unweathered dilbit appears to entrain oil at 2-3 times the rate of IFO.

\section{Gas transfer velocity results}

Figure 3 was generated by varying the amount of water in the test container and measuring the gas transfer velocity by Eq. (2). Increasing the water level resulted in larger wave heights and deeper water in the test containers. The results served two very important purposes: to determine the gas transfer velocity at the oil entrainment test conditions of $250 \mathrm{cc}$, which enables scaling our results to realworld rivers, and to serve as a method of verifying our scaling scheme in a later section of this paper. A seconddegree polynomial fit to the gas transfer velocity in terms of the water volume is shown in the plot.

In Fig. 3, four gas transfer velocity values were measured at each water volume. One can see the scatter increases as the water volume and wave height increase.

Sloshing in a tank is a phenomenon that is strongly random (Repalle 2011), and it is possible that over any GTV measurement taken through a 15-s span, significant differences could occur from other experimental runs. Kaminsky and Bogaert (2009) show that wave impacts in a sloshing tank can be of four different types: slosh, aerated, air pocket, and flip through. Wall impacts of waves with varying amounts of entrained air almost certainly affect the rate of $\mathrm{O}_{2}$ absorption. Data from Hall et al. (2012) show a marked increase in GTV values as river rapids intensity and air entrainment increase.

Container water depths were as follows: $100 \mathrm{cc}: 1.8 \mathrm{~cm}$; $300 \mathrm{cc}: 4.8 \mathrm{~cm}$; and $450 \mathrm{cc}: 6.5 \mathrm{~cm}$. 
Fig. 2 Oil mass absorbed by sediments per mass of slick per minute as a function of sediment concentration. Figure generated at a turbulence level corresponding to a GTV of $175 \mathrm{~cm} / \mathrm{h}$

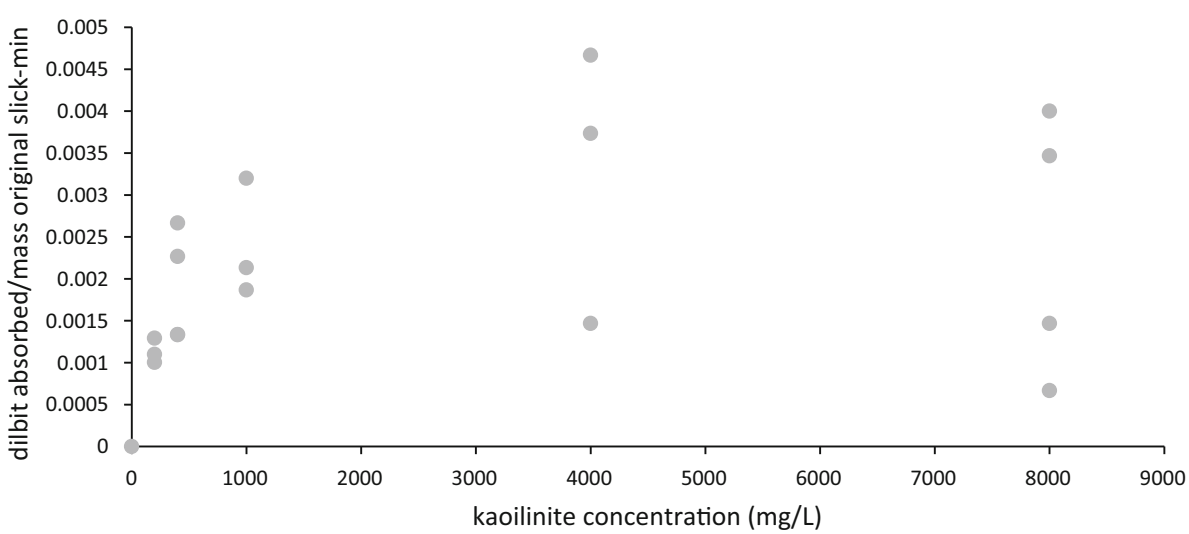

The thin black crosses show the experimental values of oil entrained. The line with short black dashes is a trend line to the experimental points. The dashed line marked as "Predicted using 0.63 power" is a test of the scaling assumption (Eq. 8). The scaling assumption is tested by beginning with the known oil entrainment and GTV values at $100 \mathrm{cc}$ of water, and then using the scaling assumption to predict the oil entrainment at larger volumes.

Figure 4 shows that the proposed scheme using 0.63 power in Eq. (8) gives a close fit to the experimental trend line, proving the validity of our scaling assumption in the tested range. Given the many assumptions used in deriving Eq. (8), the results are surprisingly good. It was found that using 0.67 power in Eq. (8) results in virtually zero error from the experimental trend line, but it is probably wiser to use 0.63 , as it is based on theoretical as well as empirical results from actual rivers.

\section{Sample case: spill of diluted bitumen in small versus large rapids}

We now demonstrate the technique by determining an upper bound on the diluted bitumen entrained in a $1000-\mathrm{kg}$ spill in a river with GTV values of $200 \mathrm{~cm} / \mathrm{h}$ (small rapids) and a river with $7000 \mathrm{~cm} / \mathrm{h}$ (large rapids). Two clay-sized sediment loads are considered: 100 and $1000 \mathrm{mg} / \mathrm{L}$. The slick is exposed to the rapids for a time of $10 \mathrm{~min}$. We demonstrate the technique step-by-step only for the moderate rapids at $100 \mathrm{mg} / \mathrm{L}$.

From Fig. 2, we can extract the laboratory entrainment values for a sediment load of $100 \mathrm{mg} / \mathrm{L}$ as about $0.0005 \mathrm{~kg} / \mathrm{kg}$-slick-min. Figure 2 was generated with a turbulence corresponding to a GTV value $175 \mathrm{~cm} / \mathrm{h}$.

We use Eq. (8) to scale the laboratory results to the river, using 0.63 as the exponent: 
Fig. 4 Results of using Eq. (8) to predict the oil entrained, based on known results at $100 \mathrm{cc}$ of water

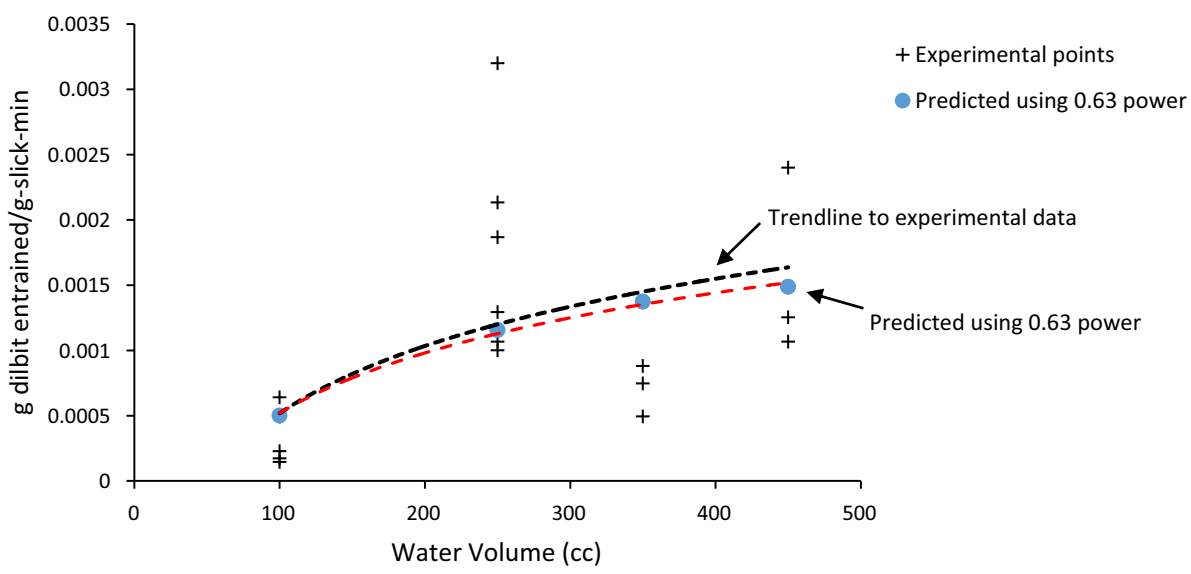

The rate of change in the mass of the slick is given by the equation (Perez et al. 2014):

$\frac{\mathrm{d} m}{\mathrm{~d} t}=-m_{R} m$

where $m$ is the mass of the slick, $t$ is time ( $\min ), m_{R}$ is the oil entrainment rate calculated in the previous step $\left(0.0005 \frac{\mathrm{kg}}{\mathrm{kg}-\mathrm{min}}\right)$.

Upon integration, the solution to this equation is:

$m=m_{o} \mathrm{e}^{-t m_{R}}$

where $\mathrm{m}$ is the mass of the slick after time $\mathrm{t}(\mathrm{min})$, and $m_{o}$ is the original slick size. After $10 \mathrm{~min}$, the mass of the slick is:

$m=1000 \mathrm{e}^{-10(0.0005)}=995 \mathrm{~kg}$

Thus, about $5 \mathrm{~kg}$ or about $0.5 \%$ of the slick is entrained by sediments in $10 \mathrm{~min}$.

Figure 5 shows the results up to $2 \mathrm{~h}$ for all of the scenarios. The plot shows the expected effect of increasing oil entrainment with sediment load and rapids intensity.

\section{Accuracy of the technique}

Due to the scatter evident in Figs. 2 and 3, the results presented in this work must be interpreted with care. As discussed previously, there are two likely sources of errors in this study: the inherent randomness of the experimental setup (and probably of real-life rivers) and the sensitivity of the results to contamination due to the small quantities of oil being measured. The authors recommend that any users of the technique calculate maximum and minimum entrainment values based on the extremes found in Fig. 2 (or one like it for oils other than dilbit). In addition, users

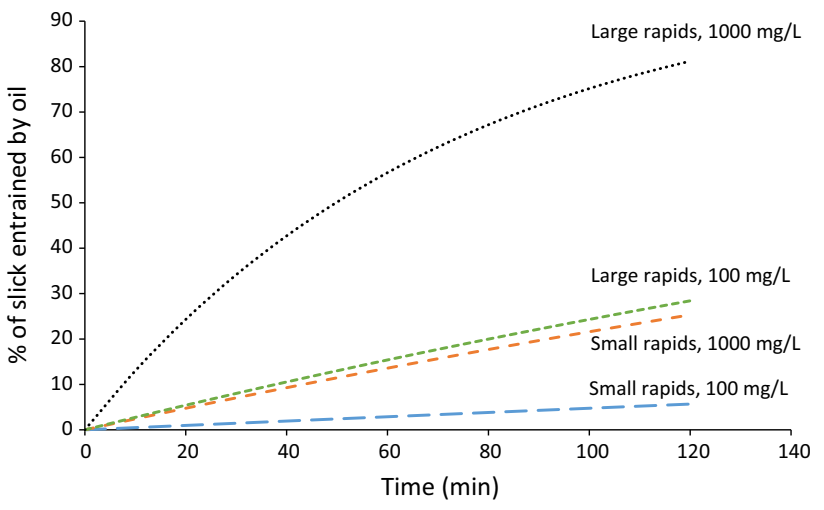

Fig. 5 Effect of turbulence and sediment load on oil entrained by sediments

may allow the exponent used in Eq. (8) to vary over a reasonable range (for example from 0.5 to 1 ) to establish a more conservative range of estimates.

\section{Estimating oil entrainment by parametric equations for $\mathrm{O}_{2}$ absorption}

Since the $\mathrm{O}_{2}$ content is such an important parameter to the health of river water, $\mathrm{O}_{2}$ absorption measurements are quite numerous. Parametric fits for oxygen absorption constants by Melching and Flores (1999) are the result of screening $\mathrm{O}_{2}$ absorption constants from 41 USGS reports involving 493 independent reaches on 166 streams in 23 states. These streams ranged from 0.00001 to $0.06 \mathrm{~m} / \mathrm{m}$ slope, flow rates from 0.0028 to $210 \mathrm{~m}^{3} / \mathrm{s}$, velocities from 0.003 to $1.83 \mathrm{~m} /$ $\mathrm{s}$, width ranging from 0.78 to $162 \mathrm{~m}$, and depth values ranging from 0.0457 to $3.05 \mathrm{~m}$.

Melching and Flores (1999) analyzed these data and developed curve fits for "pool and riffle streams" (streams made up of alternating riffles/rapids and quieter water).

For streams with discharge greater than $0.566 \mathrm{~m}^{3} / \mathrm{s}$, the aeration coefficient $\mathrm{k}_{2}$ followed the following relation: 


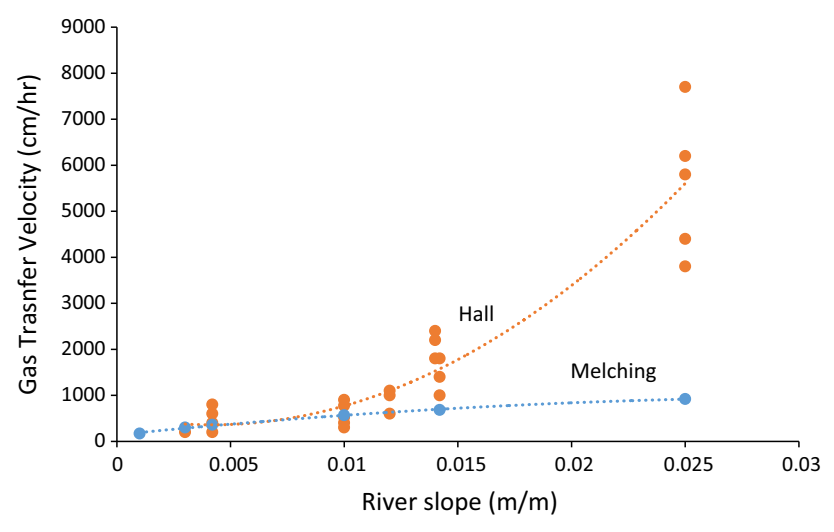

Fig. 6 Melching's equation applied to Hall's Colorado River results

$K_{2}\left(\frac{1}{\text { day }}\right)=596(V S)^{0.528} Q^{-0.136}$

where $V$ is the flow velocity in $\mathrm{m} / \mathrm{s}, S$ is the river slope in $\mathrm{m} / \mathrm{m}$, and $Q$ is the river discharge in $\mathrm{m}^{3} / \mathrm{s}$. Equation (15) has a coefficient of variation of 0.441 and a standard deviation of 5.36. The coefficient $K_{2}$ governs the change in $\mathrm{O}_{2}$ concentration $(\mathrm{mg} / \mathrm{L})$ per unit time $(\mathrm{d} C / \mathrm{d} t)$ per the relation (Langbein and Durum 1967):

$\frac{\mathrm{d} C}{\mathrm{~d} t}=K_{2}\left(C_{\mathrm{sat}}-C\right)$

where $C_{\text {sat }}$ is the $\mathrm{O}_{2}$ concentration at saturation, and $C$ is the actual $\mathrm{O}_{2}$ concentration.

Aeration coefficients $K_{2}$ (1/day) may be converted to gas transfer velocities $(\mathrm{cm} / \mathrm{h})$ by multiplying the $K_{2}$ value by the depth $(\mathrm{cm})$ and dividing by $24 \mathrm{~h} /$ day.

Since data from very turbulent rapids were not available to Melching and Flores (1999), their equation may not be a good choice for predicting GTV values in larger rapids. Data taken by Hall et al. (2012) are shown in Fig. 6 in conjunction with GTV values from Melching and Flores's (1999) equation, based on typical values for the Colorado River of $2 \mathrm{~m} / \mathrm{s}$ flow speed, $350 \mathrm{~m}^{3} / \mathrm{s}$ flow rate, and $4 \mathrm{~m}$ depth.

It is evident from Fig. 6 that for rivers with large rapids with slopes greater than about 0.01, Melching and Flores's (1999) correlation may be inappropriate. Below this slope, the equation seems to fit the data of Hall et al. (2012) well.

\section{Conclusion}

The techniques presented in this work may be used for estimating the amount of un-weathered diluted bitumen (dilbit) entrained by clay-sized suspended sediments in river rapids. The technique may be used for other types of spilled oil if laboratory oil entrainment studies are performed.

Oil entrainment may be estimated using one of two methods: by use of river gas transfer velocity (GTV) measurements or by using river parameters such as slope, discharge, and flow velocity to estimate GTV.

The sediments that attach themselves to oil will probably remain in suspension until turbulence drops, after which the oil-carrying sediments will sink to the bottom. The fate of these sunken sediments is a topic that we hope to explore in further research, as well as the behavior of other types of oil and sediments.

Acknowledgments The authors thank Ms. Alexis Ramos and Ms. Maria Hansen for their continuing support. We also wish to acknowledge Mr. Richard Crook and Mr. James Schlauch for their invaluable assistance in the laboratory, and Ms. Juliana Perez for her assistance in the laboratory and in the preparation of this text. The authors also thank Dean Shashi Kumar, Captain Joseph Poliseno, and Dr. Mark Hogan for their support of this project. Finally, the authors are grateful to the Canadian Association of Petroleum Producers for providing the diluted bitumen for this project.

\section{References}

Abril G, Commarieu M, Sottolichio A, Bretel P, Guerin F (2009) Turbidity limits gas exchange in a large macrotidal estuary. Estuar Coast Shelf Sci 83:342-348. doi:10.1016/j.ecss.2009.03. 006

Ajijolaiya LO, Hill PS, Khelifa A, Islama RM, Lee K (2006) Laboratory investigation of the effects of mineral size and concentration on the formation of oil-mineral aggregates. Mar Pollut Bull 52:920-927

American Petroleum Institute (2014). http://www.api.org/oil-andnatural-gas-overview/transporting-oil-and-natural-gas/pipeline. Accessed Nov 2014

Banerjee S, MacIntyre S (2004) The air-water interface: turbulence and scalar exchange. In: Grue J, Liu PLF, Pedersen GK (eds) Advances in coastal and ocean engineering, vol 9., PIV and water wavesWorld Scientific, Singapore, pp 181-237

Borges AV, Delille B, Schiettecatte L, Gazeau F, Abril G, Frankignoulle M (2004) Gas transfer velocities of $\mathrm{CO}_{2}$ in three European estuaries (Randers Fjord, Scheldt, and Thames). Limnol Oceanogr 49:1630-1641

Bragg JR, Owens EH (1994) Clay-oil flocculation as a natural cleansing process following oil spills: part 1-studies of shoreline sediments and residues from past spills. In: Proceedings of the 17th Arctic and Marine Oil Spill Program (AMOP) technical seminar. Environment Canada, Ontario, pp 1-23

Calleja ML, Duarte CM, Prairie Y, Agusti S, Herndl G (2009) Evidence for surface organic matter modulation of air-sea $\mathrm{CO}_{2}$ gas exchange. Biogeosciences 6:1105-1114. doi:10.5194/bg-61105-2009

Canadian Government Technical Report (2013) Properties, composition and marine spill behaviour, fate and transport of two diluted bitumen products from the Canadian oil sands. 30 Nov 2013

Danckwerts PV (1970) Gas-liquid reactions. McGraw Hill, New York

Delvigne GAL, Van del Stel JA, Sweeney CE (1987) Measurements of vertical turbulent dispersion and diffusion of oil droplets and 
oil particles. Anchorage, Alaska. US Department of the Interior, Minerals Management Service. Report no. MMS $87-111$, p 501

Edwards C, Penney D (2008) Elementary differential equations with boundary value problems, 6th edn. Prentice-Hall, Englewood Cliffs

Enbridge (2014) Enbridge Energy Partners form 10Q, filed with the Securities and Exchange Commission. Nov 2014

EPA (2013) Environmental Protection Agency web site. http://www. epa.gov/enbridgespill/pdfs/enbridge_fs_201308.pdf. Accessed Nov 2014

EPA (2014) Environmental Protection Agency web site. http://www. epa.gov/enbridgespill/. Accessed Dec 2014

Eugster W, Kling G, Jonas T, McFadden JP, Wuest A, Macintyre S, Chapin FS (2003) $\mathrm{CO}_{2}$ exchange between air and water in an Arctic Alaskan and midlatitude Swiss lake: Importance of convective mixing. J Geophys Res 108:4362. doi:10.1029/ 2002JD002653

Frew NM, Goldman JC, Dennet MR, Johnson AS (1990) Impact of phytoplankton-generated surfactants on air-sea gas exchange. J Geophys Res 95:3337-3352. doi:10.1029/JC095iC03p03337

Frost T, Upstill-Goddard RC (2002) Meteorological controls of gas exchange at a small English lake. Limnol Oceanogr 47:1165-1174

Guerin F, Abril G, Serca D, Delon C, Richard S, Delmas R, Tremblay A, Varfalvy L (2007) Gas transfer velocities of $\mathrm{CO}_{2}$ and $\mathrm{CH}_{4}$ in a tropical reservoir and its river downstream. J Mar Syst 66:161-172. doi:10.1016/j.jmarsys.2006.03.019

Guyomarch J, Merlin F, Bermanose P (1999) Oil interaction with mineral fines and chemical dispersion: behaviour of the dispersed oil in coastal or estuarine condition. Environment Canada's 22nd Arctic and Marine Oil Spill (AMOP) Technical Seminar, Calgary, Alberta, Canada, pp 137-149

Guyomarch J, Le Floch S, Merlin F-X (2002) Effect of suspended mineral load, water salinity and oil type on the size of oilmineral aggregates in the presence of chemical dispersant. Spill Sci Technol Bull 8(1):95-100

Hall R, Kennedy T, Rosi-Marshall E (2012) Air-water oxygen exchange in a large whitewater river. Limnol Oceanogr Fluids Environ 2(2012):1-11

Harris DC (2010) Quantitative chemical analysis, 8th edn. W. H Freeman, New York

Hill PS, Khelifa A, Lee E (2002) Time scale for oil droplet stabilization by mineral particles in turbulent suspensions. Spill Sci Technol Bull 8(1):73-81

Ho DT, Bliven LF, Wanninkhopf R, Schlosser P (1997) The effect of rain on air-water gas exchange. Tellus 49:149-158. doi:10.1034/ j.1600-0889.49.issue2.3.x

Ho DT, Veron F, Harrison E, Bliven LF, Scott N, McGillis WR (2007) The combined effect of rain and wind on air-water gas exchange: a feasibility study. J Mar Syst 66:150-160. doi:10. 1016/j.jmarsys.2006.02.012

Jernelov A (2010) How to defend against future oil spills. Nature 466:182-183

Kaminsky M, Bogaert M (2009) Full-scale sloshing impact tests. In: 19th International offshore engineering conference, Osaka, Japan

Khelifa A, Hill P, Lee K (2005a) Oil pollution and its environmental impact in the Arabian Gulf Region. Elsevier, Amsterdam, pp 131-145

Khelifa A, Stoffyn-Egli P, Hill PS, Lee K (2005b) Effects of salinity and clay type on oil-mineral aggregation. Mar Environ Res 59:235-254

Khelifa A, Hill P, Lee K (2005c) A comprehensive numerical approach to predict oil-mineral aggregate formation (OMA) following oil spills in aquatic environments. Int Oil Spill Conf Proc 2005(1):873-877
Langbein WB, Durum WH (1967) The aeration capacity of streams. U.S. Geological Survey Circular, 542

Lehr W (2010) Review of modeling procedures for oil spill weathering behavior. HAZMAT Division, NOAA. USA. http:// www.usgs.gov/foia/FRTG_emails/05-31-2010...Oil\%20Spill\% 20Background.pdf. Downloaded Aug 2014

Ma X, Cogswell A, Li Z, Lee K (2008) Particle size analysis of dispersed oil and oil-mineral aggregates with an automated ultraviolet epi-fluorescence microscopy system. Environ Technol 29(7):739-748

McCourt J, Shier L (1999) Interaction between oil and suspended particulate matter in the Yukon River. In: International oil spill conference proceedings, no 1, pp 1249-1252

McCourt J, Shier L (2001) Preliminary findings of oil-solids interaction in eight Alaskan rivers. In: International oil spill conference proceedings, no 2, pp 845-849

McKenna SP, McGillis WR (2004) The role of free-surface turbulence and surfactants in air-water gas transfer. Int $\mathrm{J}$ Heat Mass Transf 47(539-553):2003. doi:10.1016/j.ijheatmasstransfer.06. 001

Melching C, Flores H (1999) Reaeration equations derived from U.S. Geological Survey database. J Environ Eng (ASCE) 125(5):407-414

NY Times (2014). http://www.nytimes.com/2014/05/01/business/ energy-environment/as-new-shipping-rules-are-studied-anotheroil-train-derails.html?_r=0. Accessed Dec 2014

Payne JR, Kirstein BE, Clayton JR, Clary C, Redding R, McNabb D, Farmer G (1987) Integration of suspended particulate matter and oil transportation study. Final report, report No. MMS 87-0083, U.S. Minerals Management Service: Anchorage, Alaska

Payne JR, Claton Jr JR, McNabb Jr GD, Kirstein BE, Clary CL, Redding RT, Evans JS, Reimnitz E, Kempema EW (1989) Oilice-sediment interactions during freeze-up and break-up. Outer Continental Shelf Environmental Assessment Program, Final Reports of Principal Investigators, US Department of Commerce, NOAA, OCSEAP Final Report 64, p 382

Payne JR, Clayton JR, Kirstein BE (2003) Oil/suspended particulate material interactions and sedimentation. Spill Sci Technol Bull 8(2):201-221

Perez S, Furlan P, Hussein N, Shinn D, Crook R (2014) Interaction between oil and suspended sediments in class 1-2 rivers. In: International oil spill conference, Savanah, Georgia 5-8 May. International Oil Spill Conference Proceedings, no 1, pp 299120

Pope SB (2000) Turbulent flows. Cambridge University Press, Cambridge, p 244

Repalle N (2011) Study of sloshing tank impact pressures using level set method. Ph.D. Thesis, School of Mechanical Engineering, The University of Western Australia

Schladow SG, Lee M, Hurzeler BE, Kelly PB (2002) Oxygen transfer across the air-water interface by natural convection in lakes. Limnol Oceanogr 47:1394-1404

Stoffyn-Egli P, Lee K (2002) Formation and characterization of oilmineral aggregates. Spill Sci Technol Bull 8(1):31-44

USDOI (2014) U.S. Department of the Interior, Bureau of Land Management. http://www.blm.gov/ca/st/en/fo/folsom/rivers/ riverclass.html. Accessed Aug 2014

Vachon D, Prairie Y, Cole J (2010) The relationship between nearsurface turbulence and gas transfer velocity in freshwater systems and its implications for floating chamber measurements of gas exchange. Limnol Oceanogr 55(4):1723-1732. doi:10. 4319/lo.2010.55.4.1723

Vanoni V (2006) Sedimentation engineering. American Society of Civil Engineers, Reston

Wanninkhof R (1992) Relationship between wind speed and gas exchange over the ocean. J Geophys Res 97:7373-7382. doi:10. 1029/92JC00188 
Wanninkhof R, McGillis WR (1999) A cubic relationship between air-sea $\mathrm{CO}_{2}$ exchange and wind speed. Geophys Res Lett 26:1889-1892. doi:10.1029/1999GL900363

White F (2010) Fluid mechanics, 7th edn. McGraw-Hill Inc., New York

Zappa CJ, Asher WE, Jessup WE, Klinke J, Long SR (2004) Microbreaking and the enhancement of air-water transfer velocity. J Geophys Res 109:C08S16. doi:10.1029/ 2003JC001897
Zappa CJ, McGillis WR, Raymond PA, Edson JB, Hintsa EJ, Zemmelink HJ, Dacey WH, Ho HT (2007) Environmental turbulent mixing controls on air-water gas exchange in marine and aquatic systems. Geophys Res Lett 34:L10601. doi:10.1029/ 2006GL028790

Zhang H, Khatibi M, Zheng Y, Lee K, Li Z, Mullin J (2010) Investigation of OMA formation and the effect of minerals. Mar Pollut Bull 60:1433-1441 